University of New Mexico

UNM Digital Repository

Long Term Ecological Research Network

Long Term Ecological Research (LTER)

6-1984

Long-Term Ecological Research

James T. Callahan

Follow this and additional works at: https://digitalrepository.unm.edu/lter_reports 


\section{Long-Term Ecological} Research

\author{
James T. Callahan
}

\begin{abstract}
Research in ecology has traditionally been funded for short periods of time and pertormed at single sites, conditions not conducive to projects addressing much greater time and geographic scales. NSF's support of an experimental emphasis on long. term ecological research seeks to alleviate this discontinuity and use avaitable research resources more effectively to provide a more stable platform for the ecological sciences. (Accepted for publication 10 February 1984)
\end{abstract}

Federally supported research in the ecological sciences has most often been carried out at single sites over relatively short periods of time. Examples to the contrary are exceptional and have resulted from either special circumstances or narrowly focused, continual measurement of a few variables. The former might be exemplified by the well-known studies conducted by Bormann, Likens, and colleagues at Hubbard Brook. New Hampshire, or by Ehrlich and colleagues at Jasper Ridge, California. These projects, led by scientists recognized as leaders in their fields, have been nearly continuously conducted for more than 20 years, yet they have not been planned, proposed, reviewed, or had funds committed to them for more than three years at a time. Examples of the latter case include the records of the National Weather Service and the US Geological Survey and the permanent plots of the Continuous Forest Inventory.

Bormann and Likens (1979) from Hubbard Brook have pointed out that, except in cases of extreme degradation, it is virtually impossible to answer questions pertaining to long-term maintenance of forest productivity because historical records are usually inadequate. However, their research project, partly by virtue of its duration, has provided valuable insights into the effects on forest productivity of air pollution, forest harvesting practices, and forest developmental cycles. The intensity and scope of the studies by Ehrlich and colleagues of the Jasper Ridge colony of checkerspot butterflies are evident from a large number of Dublications (e.g., Brown and Ehrlich 1980. Ehrlich et al. 1975). These studies

Calahan is with the Division of Biotic Systems and Resources, National Science Foundation. $1800 \mathrm{G} \mathrm{St}$. NW. Washington, DC 20550. have had scientific impacts of the most fundamental nature, even to the point of suggesting redefinition of such basic terms as population and species. Interestingly, Ehrlich (1979) in another publication has commented on some of the constraints on long-term research such as turnover among personnel and the perceived necessity of obtaining results and publishing papers quickly to satisfy both academic institutions and research funding agencies.

Appraisals pointing out the inadequacy of historical environmental records and the effect of short-term support nn research output and personnel could be viewed as an indictment. Short-term research projects, alone, can serve as definitive bases neither for addressing societal concerns related to environmental biology nor for the substantial advancement of a science that deals with processes occurring over long periods of time. There is a serious contradiction between the time scales of many ecological phenomena and the support to finance their study. The problem is a difficult one. Funding cannot be guaranteed to any research undertaking for even tens of years, let alone for centuries or more. How can this pattern be broken, a pattem that acts against the consistent and reliable accumulation of sets of long-term synoptic data? What should the scientific community and the advocates of environmental biological research do to broaden the scope of research?

A first step is to define the dimensions of the problem and the key elements for its solution. Temporal and spatial scales are of critical importance. When many of the phenomena of interest occur over long periods of time, it is inappropriate to fit research on those phenomena to the typical two- to three-year planning/
LTER Publication No. 1 proposing/reviewing/funding cycle.

Even similar projects are not often comparable unless effort and resources have been devoted to making them so, This inherent tendency away from com. parability becomes more prominent among projects conducted at locations that are geographically and biologically disjunct. Directionality of some ecological processes and periodicity of others can confound comparability even further. For example, processes of aggradation and degradation are directional. They may occur continuously or by quantum changes. They may even occur concurrently. When observed over suffcient periods of time they can appear to be cyclic with building processes setting the stage for depletion processes and vice versa. The purposeful collection of high-quality data over the long term will allow generalization of ecological research results and theory over scales of time and space great enough to evaluate disturbances such as fire, grazing, deforestation, $\mathrm{CO}_{2}$ elevation, and acid precipitation.

\section{THE DEMAND FOR LONG-TERM RESEARCH}

The passage of the National Environmental Policy Act of 1969 (NEPA) created unforeseen demands on environmental biological science. When NEPA (Sec. 101.(c]) mandated that "it is the continuing policy of the Federal Govemment ... to use all practicable means and measures ... to create and maintain conditions under which man and nature can exist in productive harmony," the stage was set for federal agencies to support and promote environmental research of kinds and scopes not consid. ered earlier. The joint Ad Hoc Committee on Ecological Research (Council on Environmental Quality and Federal Council on Science and Technology) reaffirmed that previously determined course by stating that "most of the emphasis of ecological study in the past was descriptive, today we are extending our activities to assess further the effects of our actions on the ecosystems of which we are a part" (Committee on Ecological Research 1974). The same report stated furthermore that "this necessitates adding a predictive capability :.. of any long and short-term changes in these systems." The Global 2000 Report to the President (Council on Environmental Quality and Department of State 1980) stated that "in using and evaluating the Govemment's present capability for 
long-term global analysis, the Study found serious inconsistencies. in the methods and assumptions employed by various agencies."

The demand by the scientific community for support of long-term research is difficult to document in terms of concrete references. The report, "LongTerm Ecological Measurements" (National Science Foundation 1977) phrases that demand succinctly in its first sentence: "Ecology requires long-term studies." Evidence of the demand is corroborated by the value of extant longterm data sets in formulating modern ecological theory, the persistence of scientists who pursue long-term studies in the face of review and funding conditions that work against them, and the enthusiasm and level of response by the scientific community when modest offerings of such support are made.

Demand for the results of long-term ecological research is broad. The usefulness of long-term ecological research has been proven at all levels of government and in most sectors of the private economy. For instance, various commentaries have questioned the quality of the environmental impact analysis process. The often-identified primary weakness has been lack of predictive capability. Most impact analyses have read as large inventories and descriptions, and their functional ecological/environmental aspects have dealt with little more than the most obvious direct effects on ecosystems. Predictive capability is severely limited by lack of appropriate information. The lead editorial (Rajagopal 1979) of the first issue of The Environmental Professional is a thoughtful expression of this concern.

\section{ANTECEDENTS}

The roots for federal support for longterm ecological research are deeply embedded in a family of preceding efforts including national parks, wildlife refuges and preserves, and experimental forests and ranges. The Department of Energy maintains a number of national environmental research parks on some of its major holdings. The interagency Federal Committee on Research Natural Areas and its successor. the Federal Committee on Ecological Reserves, performed a major service in cataloging federal lands available for research. In the state and private sectors, similar inventories have been made by organizations like the $\mathrm{Na}$ ture Conservancy. The International Biological Program, in this country and others, used a multidisciplinary approach to studying the earth's ecological structure and function. The Man and the Biosphere Program undertook the desig. nation of an international system of biosphere reserves. In a series of studies sponsored by NSF, the scientific community, through the Institute of Ecology (TIE), undertook to identify, evaluate, and designate the field research sites in the US most appropriate for inclusion in a system of experimental ecological reserves and most capable of accommodating the requirements of such research (The Institute of Ecology 1977, 1981). This partial summary gives testament to the scope of precedents of thought and action. Programs designed specifically to implement such research have been lacking.

\section{IMPLEMENTATION}

Translation of needs, plans, and precedents for long-term ecological research into a system for its support and performance is a complex process. As a first phase in this process, NSF sponsored a series of three workshops between 1977 and 1979 to initiate and maintain close consultation with the ecological sciences community. Nearly 100 research scientists, potential users, and cooperators from the private and governmental sectors shared their knowledge, opinions. and advice with NSF. During this time the working title of the effort changed from "monitoring" to "research," having gone through "measurement" and "observation and study" along the way. This evolution of titles documents the rejection by participants of collecting data for the sake of collecting data. It reflects the insistence of scientists on the organization of research projects around ecological questions and hypotheses of value in expanding ecological theory and for solving problems of environmental resource management.

Five core areas of research were de. fined that reflect the desire of the community to orient long-term ecological research projects toward question/hypothesis formulation and resolution:

- Pattern and control of primary production (to study the energy limits of system function):

- Spatial and temporal distribution of populations selected to represent trophic structure (to sketch the major pathways of system transfer of commodities and the skeleton of system structural organization);
- Pattern and control of organic matter accumulation in surface layers and sediments (to understand the storage and processing of biological materials);

- Patterns of inorganic input and movements through soils, groundwater, and surface waters (to evaluate the interaction of geochemical and biological processes); and

- Patterns and frequency of disturbance to the research site (to compare nature and man as perturbers of natural systems).

These core research areas were intended to serve as organizing foci for individual long-term projects and to direct attention to areas for productive comparison among projects. They did not attempt to impose a traditional trophic structural approach on the study of ecological systems but rather suggest an approach organized around families of structural and functional attributes comparable among regions.

Early on it was recognized that for long-term projects to be successful, they should be divorced, to a practicable degree, from the often vagarious behavior of individuals and institutions. To ensure continuity, proposers had to document, for example, plans for continued project leadership, guarantees of site integrity and means of resolving conflicts over site use. Information stewardship had often been a significant shortcoming, so development of data management systems and site-specific reference collections were required by NSF. Since liaison with other scientists was vital, proposers were required to develop plans for information synthesis and publication, site promotion. and independent external review of each project. Detailed descriptions were not provided to define acceptable plans and mechanisms. Doing so would have constrained the proposers unnecessarily, and they were in the best position to know what devices would work at their own institutions.

These requirements and guidelines were formulated and agreed upon. An NSF information flyer (National Science Foundation 1979) announcing the emphasis was the result. This fiyer was distributed to the institutions on NSF's standard mailing lists as well as to all workshop participants and individuals who had made inquiries. Its purpose was simply to announce that NSF, through the Division of Biotic Systems and Resources (then the Division of Environmental Biology), was willing to receive proposals in the area of long-term eco- 
logical research. For the second round of funding competition, the organizational framework was already in place, and the flyer was simply updated (National Science Foundation 1980).

Responses from the scientific community were encouraging. Several hundred legitimate inquiries were received over the two rounds of competition. After careful consideration of the external peer-review process, NSF concluded that there was no fundamental reason to change the mechanisms already in place, except to recruit an advisory subcommittee (i.e., panel) having the appropriate background and expertise. From the first competition involving 29 proposals, 6 projects were funded. The 24 submissions to the second competition included 11 proposals that were essentially revisions of declines from the first competition. The second competition yielded 5 projects for which funding was recommended. Success rates were approximately $21 \%$ in both rounds.

It is difficult to draw conclusions from limited samples. However, some generalizations emerge. First, constructing such proposals is a major effort. Many groups chose not to submit once they were able to project what effort would be required. Second, the commitment required by scientists and institutions-in terms of time, facilities, research sites, etc. - could not be met by all who were interested. Finally, the level of enthusiasm expressed by applicants and interested parties was remarkably high. Support for the concept and hope for its productive progress came from a broad simple of government agencies, the private sector, and the academic community.

\section{THE SCIENCE OF LONG-TERM ECOLOGICAL RESEARCH}

In a manner reflecting the desires of the scientific community, most proposals were oriented toward testing hypotheses or answering questions of ecosystem structure and function. This orientation set these proposals distinctly apart from studies that might be called monitoring and was important in assessing potential performance. The quality and tenability of hypotheses and questions became important considerations in evaluating the proposals. The projects that were positively reviewed were those that most successfully combined the attributes of site quality. institutional and personnel capability, and meaningful hypotheses and questions.
Analysis of the successful proposals showed that the hypotheses and questions fell into several categories, including:

- The effects of physical environmental variables on the structure and the change in structure of biotic communities;

- The processes by which herbivorous populations are regulated;

- The processes that regulate the rates of accumulation and transport of decomposing organic matter;

- The processes that influence the rates at which inorganic nutrients are taken up, utilized, and released by the biota; and

- The role played by major disturbances in maintaining or changing the character of ecosystems.

\section{A Sample of Majọ Ecosystems}

Early on in the LTER planning effort it became necessary to accept that it would be impossible to sufficiently sample the ecosystems of the United States. For instance, it was completely beyond reason to consider initiating LTER projects at the 95 sites designated as experimental ecological reserves by the TIE studies. NSF relies on peer review for project selection: in the case of LTER there was no need to change that procedure. In addition to the normal attention given to the scientific criteria in proposal evaluation, site quality and institutional commitment served as a fine filter in selecting the 11 projects supported. Geographical distribution of sites or ecosystem type never became active criteria in the selection process. Yet, the resulting geographic/ecologic diversity of the research sites is so broad as not to contain duplication (Figure 1).

A theme that permeated the proposals for long-term ecological research was the analysis of disturbance-its effects and its causes. Disturbance has been characterized and categorized in several different ways. It has been seen as either chronic or acute and as natural or anthropogenic. Insightful analyses should result from comparing the effects and recovery sequences stemming from its characterization as either intrinsic or extrinsic. Intrinsic disturbances are those deriving from conditions within the ecosystem (e.g., accumulation of fuel, which would promote the spread of wildfire): extrinsic disturbances are those coming from sources outside the ecosystem (e.g., flood and drought). The plans of most of the projects include experimen- tal disturbances to be conducted after adequate predisturbance documentation. In addition, many of the projects are prepared to take advantage of natural disturbances when they occur. The result will be that experience with disturbance will be broadened and strengthened, particularly with regard to recovery iollowing measured disturbance of ecosystems that were well documented in advance.

NSF recognized early that steps would be necessary to reinforce the principle that the LTER sites would form a sample (albeit, an imperfect one) of the ecosystems of the United States. Comparability of data from site to site was seen as a key to achieving this goal. Past experience has shown that many factors can operate against achieving comparability among laboratories, ranging from the inappropriateness of some methods for some ecosystems to accommodating needs of investigators seeking answers to different questions. With this understanding, the question then becomes one of achieving comparability given those limitations. Comparability can be approached by encouraging projects to strive for similar degrees of confidence in their estimates. Such an elusive quality comes in at least two forms: statistical confidence, often expressed as error limits on estimates, and confidence in understanding the inherent limitations of the data. The second can be achieved by assuring that the conditions under which original data were taken are fully documented and permanently attached to the data. Confidence in estimates, then, is a key to interproject comparability and can release individual researchers from methodological constraints rariging from the inconvenient to the ridiculous.

\section{Networking}

To achieve such goals as comparability of data among projects, representative sampling of national ecosystems, and tests of regional- to nationalscale hypotheses, there must be regular communication among researchers working on different projects. One dictionary defines network as "an interconnected or interrelated chain. group, or system." It is in such a context that the funding and operation of LTER projects was planned. Although projects operate virtually autonomously with regard to research at their particular sites. they are prepared to accommodate mutual goals. At the encouragement of NSF. senior scientists came together in Washington. 


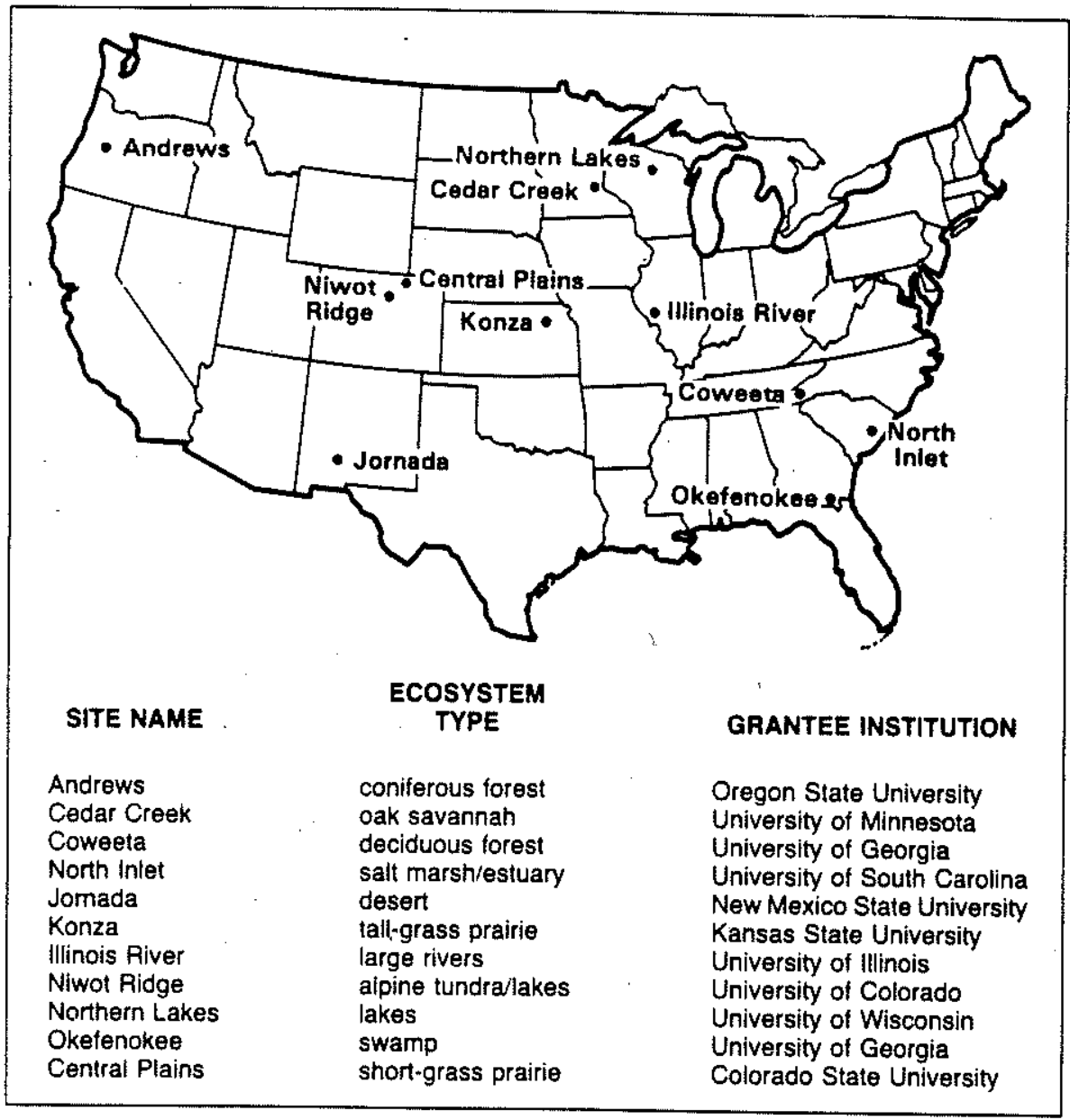

Figure 1. Sites for Long-Term Ecological Research projects funded by NSF.

DC, immediately after initial project funding in October 1980. This group very quickly constituted itself as the Steering Committee tnow. Coorúlinating Committee) for Long-Term Ecological Research and began the tasks of communication and coordination.

Since that first meeting, several others have occurred. Those since February 1982 have included representatives of the second subgroup of five projects. Further development of the mechanisms for achieving interproject coordination has led to topical workshops. These have defined methods and approaches and established collaborative research agenda. They have included scientists from projects other than LTER.

\section{THE FUTURE: OUTPUTS AND EXPECTATIONS}

There is always risk in forecasting future directions and expected benefits from basic research. Perhaps the greatest risk is that. by formalizing expectations, one may constrain the projects to fit them. The following discussion is intended to do none of those things.
The least that will come from funding for long-term ecological research projects will be careful inventories of the physical and biological states at each of the research sites. Any such inventories will have their intrinsic value increased because the research will be at least partially controlled for physical variability. Documenting the rates of various fundamental processes, such as organic decomposition, primary production. portions of herbivory, and atmospheric deposition of chemical elements will be valuable. Building upon the base provided by carefully conducted baseline studies. project teams will proceed to document the effects of disturbance on the measured variables.

Some sets of data will be very high quality and very useful. Most of the projects either possessed or had good access to files of previousiy collected information. Those older data may prove to be of ever-increasing value to the newly initiated efforts. For example. the University of Wisconsin group conducting the Northem Lakes Project knew that they had access to most of the original records of $E$. A. Birge and $C$.
Juday. In fact, they selected certain lakes for the project partly because they knew these lakes had been studied before. During their first year of operation, they began to discover how useful the old records were. It is documented that the lakes under study lie within a region receiving acid precipitation. After remeasuring the $\mathrm{pH}$ in 53 lakes, the Wisconsin group separated the lakes into three nearly distinct groups based on historic $\mathrm{pH}$ and present $\mathrm{pH}$. One group (original $\mathrm{pH}>6.4$ ) became generally more basic over the ensuing 50 years. The other two groups had been more acidic (original $\mathrm{pH}<6.4$ ), but one became more basic and the other more acidic. Further analyses showed that most morphometric and chemical variables are significantly different for the three groups. At the very least, the group has demonstrated that far more than quantity of acid precipitation must be considered when formulating a prognosis for lake response to such inputs.

Additionally, given that the site-specific studies will be conducted as they have been planned and assuming that the network continues to be developed. broad comparisons may be possible. Comparisons may include methods and techniques, ecosystem structure, process rates.

The accumulated information base at each site may prove attractive to researchers other than those funded under LTER. The existence of such an information base for a site would often relieve other investigators of the need to collect much of the requisite physical and biological contextual data that underpin research projects. Research performed by such investigators would broaden the base LTER effort. To encourage such collaborative research, the LTER projects are: actively promoting the sites to make their availability and potential known to the community at large. guaranteeing continued site security and availability, providing mechanisms to resolve possible conflicts in use of the sites by different projects, providing bithliographies and libranes of publications related to each site and its region. providing reference collections of locally obtained biological and physical specimens, and developing on-line systems for data storage, retrieval, and manipulation. By associating with LTER projects and sites that provide a data-rich research environment. individual investigators may gain a great deal. They will also be expected to cooperate by making their data and documentation available 
for inclusion in site data bases.

Much of what I have said regarding specific LTER sites also pertains to the entire LTER network. Neither NSF nor the LTER investigators intend to make the LTER data the exclusive province of scientists associated with the LTER projects. In fact. the intent is exactly the opposite, and it is hoped that the scientific community at large will come to regard the data sets as valuable resources. One might predict that in the future ecologists who wish to perform broad comparisons of ecosystem attributes would base a major proportion of the work on the existing LTER data sets. Proposals for such research would certainly be regarded as legitimate applicants for support by the NSF's Division of Biotic Systems and Resources and presumably by other research funding agencies.

\section{CONCLUSIONS}

Many of the ramifications of this longterm ecological research undertaking have been stated or implied in the foregoing discussion. In addition. NSF funding for long-term ecological research might serve as a focal point for undertakings by other public or private agencies. If the LTER research is useful and of high quality, other agencies might be willing to fund at those sites additional levels of effort to fulfill their own mandates.

Assuming a level of accomplishment through the LTER emphasis that would justify its continuation, a broad and stable platform will have been achieved upon which planning for future ecological research can be based. This has never before been available to research agencies or ecologists.

There are ecologists who assert that the development of a unified theoretical base for the science has been severely retarded by the lack of comprehensive and comparable information on a broad diversity of ecosystems. Many of those scientists would also say that the traditional patterns and rules for the planning of research and competing for funding have often been counterproductive to a science that deals with many phenomena occurring over decades or centuries. One can hope that these early steps taken to foster and underwrite long-term ecological research will lead to new and improved ecological theories that can drsimoniously encompass far larger scales of space and time than before. Scientists, planners. managers, and leg. islators may perceive the value of this long-term ecological experiment and continue to provide the impetus and enthusiasm to carry it forward. Furthermore, long-term ecological research may be useful in diagnosing and solving the increasing array of fundamental ecological problems generated by a world increasingly rich in the quantity, but ever poorer in the quality, of most human life.

\section{ACKNOWLEDGMENTS}

I thank the many NSF officers whose consultation and criticism were essential to the production of this report. The scientists who participated in workshops on long-term research performed a key role. Investigators who prepared proposals seeking LTER funding were essential. Special appreciation is expressed to Mrs. Gloria McCabe for assistance in preparing the manuscript.

\section{REFERENCES CITED}

Bormann. F. H., and G. E. Likens. 1979. Pattern and Process in a Forested Ecosys. tem. Springer-Verlag. New York.

Brown, 1. L., and P, R. Ehrlich. 1980. Population biology of the checkerspot butterfly, Euphydryas chalcedona: structure of the Jasper Ridge colony. Oecologia 47: 239 251.

Committee on Ecological Research. 1974. The Role of Ecology in the Federal Government. US Government Printing Office, Washington, DC

Council on Environmental Quality and Department of State. 1980. The Global 2000 Report to the President. US Government Printing Office. Washington. DC.

Ehrlich. P. R. 1979. The butterflies of Jasper Ridge. The CoEvolution Quarterly. Sum. mer: 50-55.

Ehrlich. P. R.. R. White, M. Singer, S. McKechnie, and L. Gilbert. 1975. Checkerspot butterflies: a historical perspective. Science 188: 221-228.

The Institute of Ecology. 1977. Experimental Ecological Reserves: A Proposed National Netw'ork. US Government Printing Office. Washington. DC.

1981. Experimental Ecological Reserves: Final Report on a National Network. The Institute of Ecology, Indianapolis. IN.

National Environmental Policy Act of 1969 as amended 142 L.S.C. 4321 er seal.

National Science Foundation. 1977. LongTerm Ecological Measurements. Report of a Conference. National Technical Informa. tion Service. Springfield. VA.

National Science Foundation. 1979. A Nen Emphasis in Long-Term Research.

National Science Foundation. 1980. LongTerm Ecological Research (LTER).

Rajagopal, R. 1979. Interdisciplinary environmental analysis. The Environmental Professional $1: 1$. 
